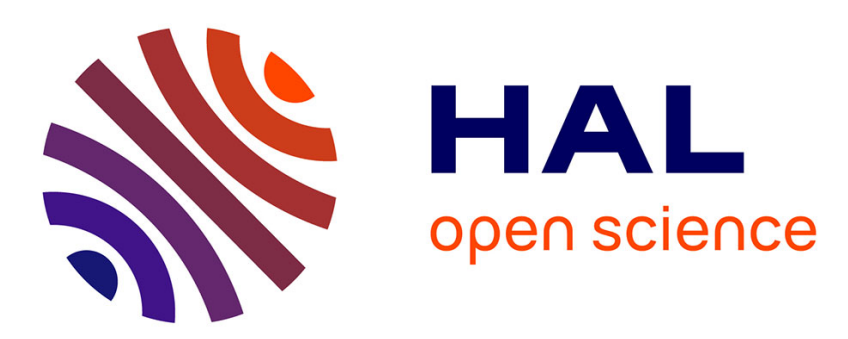

\title{
The association between preschool behavioural problems and internalizing difficulties at age 10-12 years
}

Kirsten Slemming, Merete J. Sørensen, Per H. Thomsen, Carsten Obel, Tine B. Henriksen, Karen M. Linnet

\section{- To cite this version:}

Kirsten Slemming, Merete J. Sørensen, Per H. Thomsen, Carsten Obel, Tine B. Henriksen, et al.. The association between preschool behavioural problems and internalizing difficulties at age 10-12 years. European Child and Adolescent Psychiatry, 2010, 19 (10), pp.787-795. 10.1007/s00787-010-0128-2 . hal-00618487

\section{HAL Id: hal-00618487 \\ https://hal.science/hal-00618487}

Submitted on 2 Sep 2011

HAL is a multi-disciplinary open access archive for the deposit and dissemination of scientific research documents, whether they are published or not. The documents may come from teaching and research institutions in France or abroad, or from public or private research centers.
L'archive ouverte pluridisciplinaire HAL, est destinée au dépôt et à la diffusion de documents scientifiques de niveau recherche, publiés ou non, émanant des établissements d'enseignement et de recherche français ou étrangers, des laboratoires publics ou privés. 
The association between preschool behavioural problems and internalizing difficulties at age 10-12 Years

Order of Authors: Kirsten Slemming, MD; Merete J Sørensen, MD, Ph.D.; Per Hove Thomsen, Dr.Med.Sci.; Carsten Obel, M.D., Ph.D.; Tine B Henriksen, M.D., Ph.D.; Karen M Linnet, PhD Corresponding Author's Institution: Regional Centre for Child and Adolescent Psychiatry, Risskov

\section{Introduction}

Internalizing disorders like depression and anxiety disorders are prevalent in children as well as in adults [8], and the public health impact of the disorders is significant [2]. Treatment strategies have so far proved less efficient than desirable and the possibility of early intervention needs further exploration [37]. However, the value of early intervention depends upon the identification of early symptoms or risk factors and the link between early and later symptoms.

The identification of early childhood indications of an increased risk of later childhood and adult psychopathology may provide a better understanding of the developmental pathway toward psychopathology [5;28]. This is essential for accurate prediction, timely intervention, and perhaps even prevention of later problems [17].

In very young children, diagnostic syndromes are not yet entirely agreed upon $[16 ; 16]$. Some suggest that major depressive disorder occurs as a distinct and stable depressive disorder in children as young as 2-3 years of age but that DSM diagnostic criteria for major depressive disorder (MDD) should be modified for very young children [30-32]. Others argue that, although there may be small distinctions between the two, anxiety and depressive disorders correlate to an extent that they may be treated as one internalising disorder in preadolescents [25].

Early occurrence of anxious and depressive symptoms may be associated with later anxious and depressive symptomatology [25;39;43]. This suggests stability of internalizing symptoms due to either persisting inherent disorder, persisting adverse environmental factors, or a combination of the two.

Childhood and adolescent internalizing disorders often co-occur with externalizing disorders $[4 ; 39 ; 49]$. Externalizing comorbid behaviour is associated with greater social and 
academic impairment, a more chronic course of depressive symptomatology [3], and a poor response to treatment of depression [14].

A recent review points out that current data on comorbidity in preschool children is limited to co-occurrence between broad categories of emotional and behavioural disorders [16]. The known pattern of comorbidity between depression, anxiety disorders and oppositional defiant disorder further raises the question to what extent preschool internalizing disorders are equivalent to depressive disorders in later childhood or adulthood, and furthermore how comorbid symptoms are associated with the risk of internalizing symptoms in later life [16].

Previous studies have found a significant association between preschool internalizing behaviour and internalizing difficulties in school-aged children $[27 ; 34 ; 43 ; 44]$ or young adults $[12 ; 25]$. One recent study found a similar association between preschool and school-age internalizing difficulties in girls only [42]. Most of the studies were relatively small [27;34;43;44]; only three measured comorbidity [34;42;43], and one study adjusted for parental psychopathology [34]. It is therefore not clear whether these results reflect persistency of internalizing difficulties over time, comorbid externalizing behaviour, or a chance finding in small studies. One recent study demonstrated stability over 24 months during early childhood of a diagnosis of MDD in preschool children taking into account comorbid disorders [33]. Follow up well into school age is desirable however. Further studies of the association between early and later internalizing difficulties are therefore needed.

Early externalizing difficulties may be an independent risk factor for future internalizing disorders $[12 ; 34 ; 42]$. This would suggest either a common precursor for the two dimensions, a transformation of one dimension into another, or increased environmental stress due to externalizing difficulties, resulting in increased risk of internalizing disorders. To our knowledge, it is not established whether hyperactive-distractible difficulties or hostileaggressive/disruptive difficulties or both play a role in this pathway. More detailed knowledge is important for more specific definition of at-risk children. Also, the transformation of one behavioural dimension into another is an interesting aspect to consider in understanding the complex pathways toward psychopathology across developmental stages, and this issue also needs to be further explored in future studies [16].

Our aim was to study longitudinally the association between preschool internalizing and externalizing difficulties and the risk of internalizing difficulties at 10-12 years of age, taking into account the potential effects of comorbidity and a variety of potential confounding 
factors. We expected to find that preschool internalizing difficulties were followed by internalizing difficulties at 10-12 years of age.

\section{Method}

\section{Participants, design and procedures}

The children included in this follow-up study were born between May 1, 1991 and April 30, 1992 in Aarhus, Denmark. When the children were 7 to 10 months of age, their parents were invited to participate in a study of their children's health (Fig.1). All parents of children in this age group living in the municipality of Aarhus $(\mathrm{N}=3,383)$ were contacted [46]. The response rate in this particular study was $79 \%(\mathrm{n}=2,664)$. The majority of these children were also part of a well-defined prenatal cohort, the Aarhus Birth Cohort $(\mathrm{ABC})(\mathrm{n}=2,432 ; 72 \%)$ [41;47].The $\mathrm{ABC}$ is based on unselected pregnant women who planned to give birth at the only obstetrics department in the municipality. They were recruited during early pregnancy and included the vast majority of the deliveries in the municipality of Aarhus. The additional participants in the children's health study $(\mathrm{n}=951 ; 28 \%)$ had either moved to the municipality of Aarhus after birth of the child or were non-responders from the $\mathrm{ABC}$, they were not included in the study sample.

When the children were between 3 and 4 years old, the responders of the children's health study $(n=2,664)$ received a parent-administered questionnaire concerning child behaviour, health, and development and psychosocial factors in the family. Child behaviour was measured with the Preschool Behaviour Questionnaire (PBQ) [6]. The response rate was $65 \%(\mathrm{n}=1,742)$. These children constituted the basis of the present study.

When the children were 10-12 years of age, the participating families received a parentadministered questionnaire, Strength and Difficulties Questionnaire (SDQ) [3;3], concerning child behavioural difficulties. The response rate was $79 \%(n=1,379)$. For the purpose of this study, only children with complete data on PBQ and SDQ $(n=1,336)$ were included (Fig.1). The final sample consisted of 681 boys and 655 girls. All responders were Danish-speaking, but further information on ethnicity was not obtained.

\section{Figure 1 inserted here}

\section{Preschool assessment}

Sixteen items of the PBQ were used to measure child behaviour at age 3.5 years (Table 1). The PBQ was developed in 1974 by Behar and Stringfield [6;7] as a modification of the Children's Behavior Questionnaire by Rutter [45]. It was originally designed for use by teachers to screen for preschool psychiatric difficulties but has also been used for maternal 
ratings of internalizing child behaviour [11]. In this study the PBQ was parent-administered. The PBQ and the Child Behaviour Check List (CBCL) have shown a medium to high correlation between maternal ratings of items related to child behaviour of interest in this study [10].

\section{Table 1 inserted here}

In the present study each item was rated 0 (does not apply), 1 (sometimes applies) or 2 (frequently applies). Only the answer "frequently applies" was considered a positive response. Children who scored within the highest $10^{\text {th }}$ percentile on each subscale were included in three not mutually exclusive behavioural groups, anxious-fearful $(\mathrm{n}=146 ; 11 \%)$, hyperactivedistractible $(n=98 ; 7 \%)$, and hostile-aggressive $(n=170 ; 13 \%)$. In order to evaluate the influence of comorbidity, we defined three additional mutually exclusive subgroups of the three preschool behavioural groups: anxious-fearful symptoms without comorbidity $(\mathrm{n}=104$; $8 \%$ ), hyperactive-distractible symptoms without comorbidity $(\mathrm{n}=52 ; 4 \%)$, and hostileaggressive symptoms without comorbidity $(\mathrm{n}=110 ; 8 \%)$.

To expand the scale measuring preschool internalizing difficulties, we defined an additional scale, an anxious-fearful-depressive scale $(\mathrm{n}=129 ; 10 \%)$, using two additional questions from the PBQ concerning anxious/depressive symptoms in the children (Table 1).

\section{School-age assessment}

When the children were 10 to 12 years old, parents completed the Danish version of the Strength and Difficulties Questionnaire (SDQ) [40]developed by Goodman [19].

SDQ is a 25-item instrument for screening of emotional and behavioural problems in children and adolescents. The instrument consists of five subscales. Because the present study addresses internalizing difficulties, only the subscales regarding emotional difficulties is of interest in the present study.

Each item was rated 0 (does not apply), 1 (sometimes applies) or 2 (frequently applies). Based on the recommended cut-off score on the SDQ emotional scale, children were categorized as being non-emotional (score $0-3 ; \mathrm{n}=1,133 ; 85 \%$ ), borderline emotional (score $4 ; \mathrm{n}=89 ; 7 \%)$ or emotional (score $5-10 ; \mathrm{n}=114 ; 8 \%$ ).

Previous studies show a high reliability and validity of the SDQ as a screening instrument [20;21]. Parental SDQ predicts ICD-10 and DSM-IV diagnoses reliably [19].

\section{Potential confounding factors}

Information about potential confounding factors (gender of the child, maternal education, parental cohabitation and employment, and serious parental illness) was obtained simultaneously with the preschool data collection. Information about history of parental 
psychiatric admission (in- or outpatient treatment) was obtained from the Danish Psychiatric Case Register when the preschool data was collected [36].

\section{Table 2 inserted here}

\section{Attrition analyses}

Mothers of children who were included in the Aarhus Birth Cohort but were non-responders at the follow-up at 8 months (The Child Health Study) or 3.5 years (The Preschool Study) have previously been reported to be younger and with shorter educations compared with responders [29]. Compared with responders the non-responders in the school-age study ( $\mathrm{n}=$ 364) were more likely to have mothers with lower levels of education and parents who did not live together. No preschool differences were found regarding parental employment, gender of the child, serious parental illness, and parental psychiatric hospitalization.

\section{Data analyses}

The univariate and adjusted associations between preschool categories of behaviour and school-aged emotional difficulties were evaluated in a multinomial logistic regression model and expressed as odds ratios (OR) with 95\% confidence intervals (95\% CI) (Table 3). Similar analyses were performed with the mutually exclusive preschool categories (without comorbidity). Previously reported risk factors for internalizing disorders (see Table 2) were considered potential confounders in the analyses and were a priori included in the multivariate logistic regression model as a number of dummy variables equal to the number of categories minus one [13]. Missing information within a variable was assigned a separate category within each variable.

We also analyzed the association between internalizing difficulties in preschool and school-age after excluding children of parents with a history of psychiatric hospitalizations and without serious parental illness (Table 3).

The results were considered statistically significant at a two-sided $P$ value of less than 0.05 .

Data were analyzed by using the statistical package of STATA intercooled [1].

\section{Results}

\section{Preschool single items and school age emotional difficulties}

The distribution between the PBQ behavioural items and the SDQ emotional categories is presented in Table 1.

In the anxious-fearful scale, items related to being shy, nervous and fearful or afraid were significantly associated with school-age borderline or emotional difficulties $(P$ value $<0.05)$. 
The two items related to preschool depressive/anxious behaviour were also significantly associated with school-age emotional difficulties.

All of the single items related to hostile-aggressive and hyperactive-distractible behaviour, except impulsivity, were also significantly associated with school-age borderline or emotional difficulties.

\section{Confounding factors}

The distribution of potential confounding factors in the preschool and school-age behavioural groups is shown in Table 2. No apparent associations were found between preschool anxiousfearful behaviour and potential confounding factors. Preschool hyperactive-distractible behaviour was more often reported when the mother was less educated (basic school only), when the parents were not cohabiting, and when they were unemployed. Boys more often had preschool hostile-aggressive behaviour.

School-age emotional difficulties were more common with less maternal education, parental unemployment, serious parental illness, and when the parents were not living together. School-age borderline emotional difficulties were also more common when the parents were not cohabiting.

Children with missing information on parental employment, co-habitant status, and serious illness were similar to children with complete data with respect to gender of the child, maternal educational level, and presence of a parental psychiatric diagnosis.

\section{Univariate and adjusted analyses}

Preschool children with anxious-fearful and hostile-aggressive behavioural problems had approximately twice the risk of emotional difficulties or borderline emotional difficulties at age 10-12 compared with well-adjusted preschool children at age 3.5 years, even after adjustment for confounding (Table 3).

In the univariate analyses, hyperactive-distractible children also had twice the risk of later emotional difficulties, but after adjustment the results from the multivariate analyses became statistically insignificant (OR 1.5; 95\% CI 0.8-2.3) (Table 3).

The results were unchanged in sub-analyses of the mutually exclusive preschool groups: anxious-fearful without comorbidity (borderline emotional: OR 2.1; 95\% CI 1.0-4.2; $P<0.05$ ) (emotional: OR 2.1; 95\% CI 1.1-4.0), hyperactive-distractible without comorbidity (borderline emotional: OR 1.4; 95\% CI 0.5-4.2) (emotional: OR 1.5; CI 0.6-3.8), and hostileaggressive without comorbidity (borderline emotional: OR 2.3; 95\% CI 1.1-4.5) (emotional: OR 2.4; 95\% CI 1.3-4.7). 
When analyses were performed restricted to children with no parental history of psychiatric hospitalizations and no serious parental illness, the associations remained essentially unchanged (Table 3).

\section{Table 3 inserted here}

\section{Discussion}

In this study we found an association between both preschool anxious-fearful and hostileaggressive behaviour and later emotional difficulties at age 10-12 years. Comorbid difficulties within each behavioural group did not explain these findings.

The apparent association between preschool externalizing hyperactive-distractible behaviour and later emotional difficulties in the univariate analyses was not statistically significant when controlled for socio-demographic factors and family characteristics.

Our findings of an association between preschool internalizing behaviour and later emotional difficulties support our study hypothesis as well as findings from other studies $[12 ; 27 ; 34 ; 43 ; 44]$ and indicate some degree of internalizing symptom stability. This may be due to either persistent inherent disorder, difficulty of the child, or continuous stressful life circumstances or a combination of the two. In contrast with previous studies, we were able to evaluate whether comorbidity was the explanation for the associations. We also carried out more extensive adjustments for socio-demographic factors and family characteristics than most other studies have done.

We were able to categorize preschool externalizing behaviour into hostile-aggressive and hyperactive-distractible behaviour, and we found that only hostile-aggressive behaviour was significantly associated with school-age internalizing difficulties.

Our single-item analyses also indicate that particularly hostile-aggressive items related to peer-interaction difficulties (fights, bullies, etc.) are associated with school-age emotional difficulties. This has also been indicated by previous cross-sectional and small studies on bullying behaviour and internalizing difficulties in both childhood [18;48] and adolescence [9].

We believe that we have been able to present more detailed data about internalizing symptom stability, different comorbidity patterns, including lack of comorbidity, than most previous studies in this field. Our study suggests that preschool internalizing disorders can be equivalent to internalizing disorders in later childhood. Hostile-aggressive behaviour may lead to internalizing disorder due to increased environmental stress, a common precursor for the two dimensions or a longitudinal transformation of one behavioural dimension into 
another in later childhood. This is an additional finding of what we expected. Our findings support the view that at least some degree of hyperactive and distractible behaviour is normal in 2-3 year old children and should not be considered a risk factor for future internalizing problems.

Our results indicate the possibility of preventing later depressive and anxious psychopathology and that intervention against internalizing as well as externalizing symptoms in early childhood may be of importance. However, because most symptomatic preschool children seem to grow out of their symptoms, there is a need to investigate further, which children need early intervention. Additionally, in the present study most school-age children with internalizing symptoms did not display symptoms in the preschool study. Therefore, the effort to detect and intervene against emotional symptoms should probably be maintained throughout childhood.

\section{Strengths and limitations}

Our study has several advantages over many of the previous studies in this field. The results are based on a large study population and include detailed information about comorbidity and potential confounding factors, which are needed to address questions about nosology, comorbidity and epidemiology in preschool psychiatric disorders[16]. It is a longitudinal community-based study with exposure measures collected prospectively, thereby eliminating risk of differential recall. The association under study may differ between populations, and the present study is the first known Scandinavian study of its kind and one of the first studies in the Nordic countries [42]. Health care services in the Nordic countries differ from services in many other countries by being essentially free of charge for all inhabitants. This may influence the natural course of psychiatric disorders because access to intervention is less restricted and symptom stability may therefore be less evident. Studies conducted in different countries and settings are therefore important.

Some limitations must be taken into account when interpreting the results. We attempted to adjust for the potential influence of parental psychopathology on internalizing difficulties. This was done by information from the nationwide Danish Psychiatric Registry in which all psychiatric diagnoses and severity are reported. This adjustment may be incomplete because parental psychiatric in- or outpatients are crude measures of parental psychopathology as risk factors for behavioural disorders. One previous study did, however, account for this factor in a similar manner [35].

Families invited to participate in the follow-up study when the child was 3.5 years old were responders from an earlier study when the children were 7-10 months old. Similarly, 
only responders of the 3.5-year follow-up were invited to participate in the follow-up when the children were 10-12 years old. This recruitment procedure may potentially cause selection bias, but only if non-responding families had children with no symptoms at age 3.5 years and many symptoms at age of 10-12 years or vice versa. Such strong associations in the nonresponders seem somewhat unlikely. However, the non-responders were more likely to be families with low maternal education and single mothers. If the children of non-responders have a higher frequency of behavioural difficulties compared with responders, and in addition have fewer resources to intervene, non-responders may have an even stronger association between early and later symptoms than our results indicate. Nevertheless, the frequency of behavioural problems reported by the mother in the preschool study $(22 \%)$ was similar to that reported previously $[15 ; 26]$.

Our study group consisted almost entirely of Caucasians and results may not apply to children of other ethnic groups.

Information on child behaviour was based on parental reports. In general, multiinformant-reports are considered most reliable in assessment of childhood difficulties [24] and self-reports have highly contributed to our knowledge of internal states in children as young as 5 or 6 years [23]. The possibility exists, that parental report reflects the parent'smental state or the parent-child relationship in addition to the symptoms inherent in the child. In this case the continuity measured may be the continuity of the parent'smental state or the parent-child relationship. However, the ability to express emotions on a self-report basis requires a certain level of thought-processing that preschool children do not posses, and in general parents are considered valid informers of child internalizing problems at that age unless the parent him- or herself suffers from MDD [38].

We were able to compare child behaviour using two different instruments because the construction of the questions related to internalizing behaviour in PBQ and SDQ is very similar. However, instruments applicable for both age groups (e.g. the CBCL) may give more comparable results than the use of two different instruments, had they been available. We used the PBQ and SDQ because there was no other validated Danish short behaviour questionnaires at the time when the study and follow-up was initiated. It would have been valuable to have had more detailed information on preschool as well as school-age internalising behaviour. Such information might help further narrow down the group of children at risk of future problems. However, such instruments were not available, nor was it considered feasible to increase the length of questionnaire in this sample, which had already taken part in several research projects. More detailed instruments are becoming more 
available thanks to the increasing focus on very early presentation of depressive disorders [30]. The study was purely associational thus implications regarding causal pathways cannot be drawn based on the findings.

\section{Clinical and research implications}

There is an increasing public interest in the possibility that early intervention or preventive efforts could reduce the severity or even prevent mental disorders later in life [22]. Our findings suggest an association between preschool internalizing behaviour, hostile-aggressive behaviour, and internalizing difficulties in later life. Thus, very early intervention may be possible, although there is a need to further narrow down the group at risk. More attention should be drawn both to preschool internalizing as well as hostile-aggressive behaviour, but our finding of an association between preschool hostile-aggressive behaviour and internalizing difficulties in later life is new and needs to be studied further. 
1. StataCorp. 2003. Stata Statistical Software: Release 8.0. (8.0). 2003. College Station, TX: Stata corporation.

Ref Type: Computer Program

2. Andrews G, Szabo M, Burns J (2002) Preventing major depression in young people. British Journal of Psychiatry 181:460-462

3. Angold A, Costello EJ, Erkanli A (1999) Comorbidity. Journal of Child Psychology and Psychiatry 40:57-87

4. August GJ, Realmuto GM, MacDonald AW, III, Nugent SM, Crosby R (1996) Prevalence of ADHD and comorbid disorders among elementary school children screened for disruptive behavior. Journal of Abnormal Child Psychology 24:571-595

5. Bayer JK, Hiscock H, Ukoumunne OC, Price A, Wake M (2008) Early childhood aetiology of mental health problems: a longitudinal population-based study. Journal of Child Psychology and Psychiatry 49:1166-1174

6. Behar L (1977) The Preschool Behaviour Questionnaire. Journal of Abnormal Child Psychology 5:265-275

7. Behar L, Stringfield S (1974) A Behaviour Rating Scale for the Preschool Child. Development and psychopathology 10:601-610

8. Birmaher B, Ryan ND, Williamson DE, Brent D, Kaufman J (1996) Childhood and adolescent depression: a review of the past 10 years. Part II. Journal of the American Academy of Child and Adolescent Psychiatry 35:1575-1583

9. Brunstein Klomek A, Marrocco F, Kleinman M, Schonfeld IS, Gould MS (2007) Bullying, depression, and suicidality in adloescents. Journal of the American Academy of Child and Adolescent Psychiatry 46:40-49

10. Campbell SB (1987) Parent-referred problem three-year-olds: developmental changes in symptoms. Journal of Child Psychology and Psychiatry 28:835-845

11. Campbell SB, Ewing LJ (1990) Follow-up of hard-to-manage preschoolers: adjustment at age 9 and predictors of continuing symptoms. Journal of Child Psychology and Psychiatry 31:871-889 
12. Caspi A, Moffitt TE, Newman DL, Silva PA (1996) Behavioral observations at age 3 years predict adult psychiatric disorders. Longitudinal evidence from a birth cohort. Archives of General Psychiatry 53:1033-1039

13. Clayton D, Hills M (1993) Statistical Models in Epidemiology. Oxford University Press,

14. Curry J, Rohde P, Simons A, Silva S, Vitiello B, Kratochvil C, Reinecke M, Feeny N, Wells K, Pathak S, Weller E, Rosenberg D, Kennard B, Robins M, Ginsburg G, March J (2006) Predictors and moderators of acute outcome in the Treatment for Adolescents with Depression Study (TADS). Journal of the American Academy of Child and Adolescent Psychiatry 45:1427-1439

15. Earls F (1980) Prevalence of behavior problems in 3-year-old children. A crossnational replication. Archives of General Psychiatry 37:1153-1157

16. Egger HL, Angold A (2006) Common emotional and behavioral disorders in preschool children: presentation, nosology, and epidemiology. Journal of Child Psychology and Psychiatry 47:313-337

17. Ford T, Goodman R, Meltzer H (2004) The relative importance of child, family, school and neighbourhood correlates of childhood psychiatric disorder. Social Psychiatry and Psychiatric Epidemiology 39:487-496

18. Glew GM, Fan MY, Katon W, Rivara FP, Kernic MA (2005) Bullying, psychosocial adjustment, and academic performance in elementary school. Archives of Pediatric and Adolescent Medicine 159:1026-1031

19. Goodman R (2001) Psychometric properties of the strengths and difficulties questionnaire. Journal of the American Academy of Child and Adolescent Psychiatry 40:1337-1345

20. Goodman R, Ford T, Simmons H, Gatward R, Meltzer H (2000) Using the Strengths and Difficulties Questionnaire (SDQ) to screen for child psychiatric disorders in a community sample. British Journal of Psychiatry 177:534-539

21. Goodman R, Renfrew D, Mullick M (2000) Predicting type of psychiatric disorder from Strengths and Difficulties Questionnaire (SDQ) scores in child mental health clinics in London and Dhaka. European Child \& Adolescent Psychiatry 9:129-134

22. Harrington R, Clark A (1998) Prevention and early intervention for depression in adolescence and early adult life

15. Eur Arch Psychiatry Clin Neurosci 248:32-45

23. Ialongo NS, Edelsohn G, Kellam SG (2001) A further look at the prognostic power of young children's reports of depressed mood and feelings. Child Development 72:736747

24. Jensen PS, Salzberg AD, Richters JE, Watanabe HK (1993) Scales, diagnoses, and child psychopathology: I. CBCL and DISC relationships. Journal of the American Academy of Child and Adolescent Psychiatry 32:397-406 
25. Karevold E, Røysamb E, Ystrom E, Mathiesen KS (2009) Predictors and pathways from infancy to symptoms of anxiety and depression in early adolescence. Developmental psychology 45:1051-1060

26. Larson CP, Pless IB, Miettinen O (1988) Preschool behavior disorders: their prevalence in relation to determinants. Journal of Pediatrics 113:278-285

27. Lavigne JV, Arend R, Rosenbaum D, Binns HJ, Christoffel KK, Gibbons RD (1998) Psychiatric disorders with onset in the preschool years: I. Stability of diagnoses. Journal of the American Academy of Child and Adolescent Psychiatry 37:1246-1254

28. Ledingham JE, Schwartzman AE (1984) A 3-year follow-up of aggressive and withdrawn behavior in childhood: preliminary findings. Journal of Abnormal Child Psychology 12:157-168

29. Linnet KM, Obel C, Bonde E, Thomsen PH, Secher NJ, Wisborg K, Henriksen TB (2006) Cigarette smoking during pregnancy and hyperactive-distractible preschoolers: a follow up study. Acta Paediatrica 95:694-700

30. Luby JL (2002) Preschool major depressive disorder: Preliminary validation fro developmentally modified DSM-IV criteria. J Am Acad Child Adolesc Psychiatr 41:928-937

31. Luby JL, Heffelfinger A, Mrakotsky C, Brown K, Hessler MJ, Wallis JM, Spitznagel E (2003) The clinical picture of depression in preschool children. J Am Acad Child Adolesc Psychiatr 41:340-348

32. Luby JL, Mrakotsky C, Heffelfinger A, Brown K, Spitznagel E (2004) Characteristics of depressed preschoolers with and without anhedonia: Evidence for a melancholic depressive subtype in young children. Am J Psychiatry 161:1998-2004

33. Luby JL, Si X, Belden AC, Tandon M, Spitznagel E (2009) Preschool depression. Homotypic continuity and course over 24 months. Archives of General Psychiatry 66:897-905

34. Mesman J, Bongers IL, Koot HM (2001) Preschool developmental pathways to preadolescent internalizing and externalizing problems. Journal of Child Psychology and Psychiatry 42:679-689

35. Mesman J, Koot HM (2001) Early preschool predictors of preadolescent internalizing and externalizing DSM-IV diagnoses. Journal of the American Academy of Child and Adolescent Psychiatry 40:1029-1036

36. Munk-Jorgensen P, Kastrup M, Mortensen PB (1993) The Danish psychiatric register as a tool in epidemiology. Acta Psychiatrica Scandinavica 370:27-32

37. National Collaborating Centre for Mental Health. Depression in children and young people. Identification and management in primary, community and secondary care. National Institute for Clinical Excellence . 2010. The British Psychological Society. Ref Type: Electronic Citation

38. Nauta MH, Scholing A, Rapee RM, Abbott M, Spence SH, Waters A (2004) A parentreport measure of children's anxiety: psychometric properties and comparison with 
child-report in a clinic and normal sample. Behaviora Research and Therapy 42:813839

39. Nordahl HM, Ingul JM, Nordvik H, Wells A (2007) Does maternal psychopathology discriminate between children with DSM-IV generalised anxiety disorder or oppositional defiant disorder? The predictive validity of maternal axis I and axis II psychopathology. European Child \& Adolescent Psychiatry 16:87-95

40. Obel C, Dalsgaard S, Stax H, Bilenberg N (2003) Spørgeskema om barnets styrker og vanskeligheder (SDQ-Dan). Ugeskrift for Læger 165:462-465

41. Obel C, Henriksen TB, Hedegaard M, Secher NJ, Ostergaard J (1998) Smoking during pregnancy and babbling abilities of the 8-month-old infant. Paediatric and Perinatal Epidemiology 12:37-48

42. Pihlakoski L, Sourander A, Aromaa M, Rautava P, Helenius H, Sillanpaa M (2006) The continuity of psychopathology from early childhood to preadolescence: a prospective cohort study of 3-12-year-old children. European Child \& Adolescent Psychiatry 15:409-417

43. Rende RD (1993) Longitudinal relations between temperament traits and behavioral syndromes in middle childhood. Journal of the American Academy of Child and Adolescent Psychiatry 32:287-290

44. Rubin KH, Hymel S, Mills RSL, Rose-Krasnor L (1991) Conceptualizing Different developmental pathways to and from social isolation in childhood. In: Cicchetti D, Toth SL (eds) Internalizing and externalizing expressions of dysfunction. Lawrence Erlbaum Associates, Rochester, pp 91-122

45. Rutter M (1967) A children's behaviour questionnaire for completion by teachers: preliminary findings. Journal of Child Psychology and Psychiatry 8:1-11

46. Skajaa, E. Sundhedsprofil af småbørn og småbørnsfamilier i Århus. 4-124. 1992. Dansk Institut for Sundheds- og Sygeplejeforening; Perinatal Epidemiologisk Forskningsenhed.

Ref Type: Thesis/Dissertation

47. Sondergaard C, Henriksen TB, Obel C, Wisborg K (2001) Smoking during pregnancy and infantile colic. Pediatrics 108:342-346

48. Sourander A, Jensen P, Rönning JA, Niemelä S, Helenius H, Sillanmäki L, Kumpulainen K, Piha J, Tamminen T, Moilanen I, Almqvist F (2007) What is the early adulthood outcome of boys who bully or are bullied in childhood? The Finnish "From a boy to a man" study. Pediatrics 120:397-404

49. Zoccolillo M (1992) Co-occurrence of conduct disorder and its adult outcomes with depressive and anxiety disorders: a review. Journal of the American Academy of Child and Adolescent Psychiatry 31:547-556

Fig. 1. Flowchart of the follow-up study from the Child Health study, Preschool Study and to the final School Age Study. 


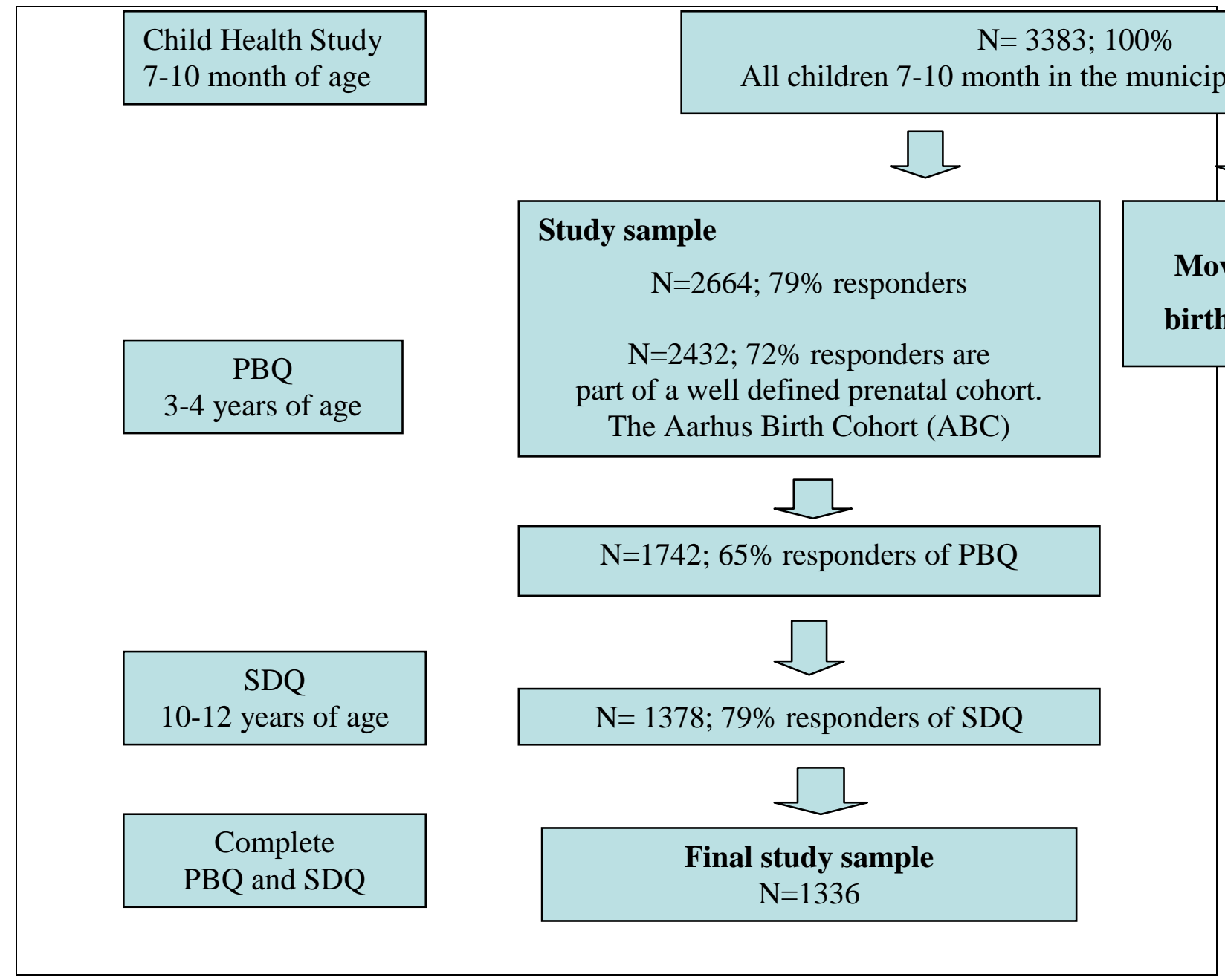

PBQ: Preschool Behavior Questionnaire

SDQ: Strength and Difficulties Questionnaire

T)

) single items and the

Strength and Difficulties Questionnaire (SDQ) categorised into borderline emotional $(n=89)$ and emotional difficulties $(\mathrm{n}=114)$.

\section{SDQ}

$\underline{\text { PBQ }}$

Borderline

Emotional

$\mathrm{N}$

$\mathrm{n}(\%)$

n $(\%)$ 


\section{Anxious-fearful scale}

Shy and nervous

No

1,325

$88(6.6)$

$110(8.3)$

11

$1(9.1)$

$4(36.4)$

Yes

Fearful/afraid of new things/ situations

No

$83(6.4)$

$108(8.3)$

Yes

39

$6(15.4)$

$6(15.4)$

Cries easily

No

1,251

$81(6.5)$

$105(8.4)$

Yes

85

$8(9.4)$

$9(10.6)$

Gives up easily

No

$85(6.6)$

$108(8.3)$

Yes

42

$4(9.5)$

$6(14.3)$

\section{Hostile-aggressive scale}

Fights with other children/hits them

No

1,326

$88(6.6)$

$108(8.3)$

Yes

10

$1(10.0)$

$6(22.2)$

Pinches and fights others when upset

No

1,309

$86(6.6)$

$111(8.4)$

Yes

27

$3(11.1)$

$3(27.3)$

Kicks or hits out at other children

No

1,325

$89(6.7)$

$98(7.9)$

Yes

11

0

$16(17.6)$

Destroys own or others` belongings 
No

Yes

15

Bullies other children

No

Yes

Does not share toys

No

1,294

Yes

\section{Hyperactive-distractible scale}

Restless/runs about, does not keep still

No

Yes

More active than others, in full swing

No

1,245

91

Yes

Poor concentration/attention span

No

1,291

Yes

Impulsive, acts before thinking

No

1,257

79

42
88 (6.7)

$1(6.7)$

3 (20.0)

$111(8.4)$

$110(8.4)$

4 (20.0)

$4(20.0)$

$108(8.3)$

$6(14.3)$

$4(9.5)$ 
No

Yes

Tends to worry

No

Yes
4

$1(25.0)$

$2(50.0)$

1,319

88 (6.7)

$106(8.3)$

15

$1(6.7)$

$8(53.3)$ 


\section{TABLE 2}

The distribution of the cohort characteristics by the preschool PBQ behavioural groups and by the school age SDQ groups.

\section{$\underline{\text { PBQ }}$}

Anxious-fearful Hostile-aggressive Hyperactive-distractible

\begin{tabular}{|c|c|c|c|}
\hline & $\mathrm{n}=146$ & $\mathrm{n}=170$ & $\mathrm{n}=98$ \\
\hline $\mathrm{N}$ & $\mathrm{n}(\%)$ & $\mathrm{n}(\%)$ & n (\%) \\
\hline
\end{tabular}

Maternal education

$>10$ years

964

$97(10.1)$

$116(12.0)$

$52(5.4)$

Basic school only

372

$49(13.2)$

$54(14.5)$

$46(12.4)$

Parental cohabitation $^{1}$

$\begin{array}{lrrrr}\text { Yes } & 1,155 & 124(10.7) & 140(12.1) & 75(6.5) \\ \text { No } & 161 & 18(11.1) & 24(14.9) & 21(13.0)\end{array}$

Parent unemployment ${ }^{2}$

$\begin{array}{lrrrr}\text { No } & 1,061 & 106(10.0) & 134(12.6) & 68(6.4) \\ \text { Yes } & 219 & 29(10.1) & 29(13.2) & 28(12.8)\end{array}$

Serious parental illness ${ }^{3}$

$\begin{array}{rrrrr}\text { No } & 1,225 & 124(10.1) & 154(12.6) & 90(7.3) \\ \text { Yes } & 51 & 9(17.6) & 7(13.7) & 4(7.8)\end{array}$

Parent psychopathology

$\begin{array}{lrrrr}\text { No } & 1,301 & 121(9.3) & 167(12.8) & 96(7.3) \\ \text { Yes } & 35 & 4(11.4) & 3(8.6) & 2(5.7) \\ \text { Girl } & 655 & 73(11.1) & 63(9.6) & 40(6.1) \\ & & & 107(15.7) & 58(8.5)\end{array}$


Boy

681

$73(10.7)$

Note: Missings: cohabitants ${ }^{1:} 20 ;$ unemployment $^{2:} 56$; serious parental illness ${ }^{3}: 60$. 
TABLE 3

Univariate and adjusted associations between preschool PBQ behaviour and school-aged SDQ borderline emotional $(\mathrm{n}=105)$ and emotional difficulties $(\mathrm{n}=136)$ presented as odds ratio $(\mathrm{OR})$ with $95 \%$ confidence intervals (CI). Multinomial logistic regression models. $\mathrm{N}=1,336$. 
Preschool Behaviour Questionnaire (PBQ)

\begin{tabular}{|c|c|c|c|c|}
\hline & & Anxious- & $\underline{\text { Hostile- }}$ & Hyperactive- \\
\hline School-aged Strength and & & fearful & aggressive & distractible \\
\hline Difficulties Questionnaire & & $(n=146)$ & $(\mathrm{n}=170)$ & $(n=98)$ \\
\hline (SDQ) & Nto & OR & OR & OR \\
\hline & $\mathrm{t}$ & $(95 \% \mathrm{CI})$ & $(95 \% \mathrm{CI})$ & $(95 \% \mathrm{CI})$ \\
\hline
\end{tabular}

Univariate associations

\begin{tabular}{|c|c|c|c|c|c|c|c|}
\hline \multirow{3}{*}{ No emotional } & \multicolumn{3}{|c|}{1} & \multirow[b]{2}{*}{13} & \multirow[b]{3}{*}{1} & \multirow[b]{3}{*}{76} & \multirow[b]{3}{*}{1} \\
\hline & 1,1 & & & & & & \\
\hline & 33 & 0 & 1 ref. & \multirow[t]{2}{*}{0} & & & \\
\hline & & 8 & & & & & \\
\hline \multirow[t]{2}{*}{ Borderline emotional } & \multirow{3}{*}{89} & 1 & $2.1(1.2-$ & \multirow{3}{*}{17} & \multirow[t]{2}{*}{$1.8(1.0-$} & \multirow{3}{*}{8} & \multirow[t]{2}{*}{$1.4(0.6-$} \\
\hline & & & & & & & \\
\hline difficulties & & 6 & 3.7) & & $3.2)^{*}$ & & 2.9) \\
\hline \multirow{3}{*}{ Emotional difficulties } & \multirow{3}{*}{114} & 1 & $2.3(1.4-$ & \multirow{3}{*}{23} & $2.0(1.2-$ & \multirow{3}{*}{14} & $1.9(1.1-$ \\
\hline & & & & & & & \\
\hline & & 6 & $3.8)$ & & $3.3)$ & & 3.6) \\
\hline
\end{tabular}

Adjusted associations**

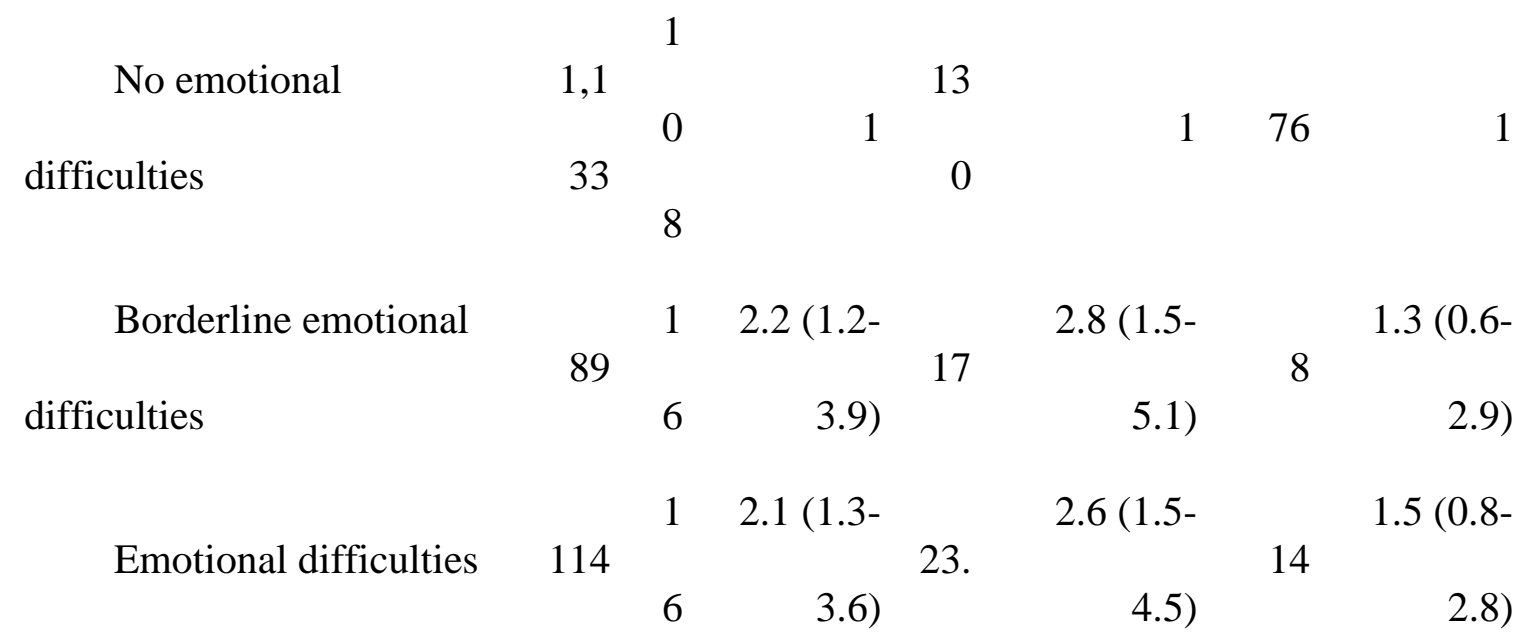

Restricted associations***

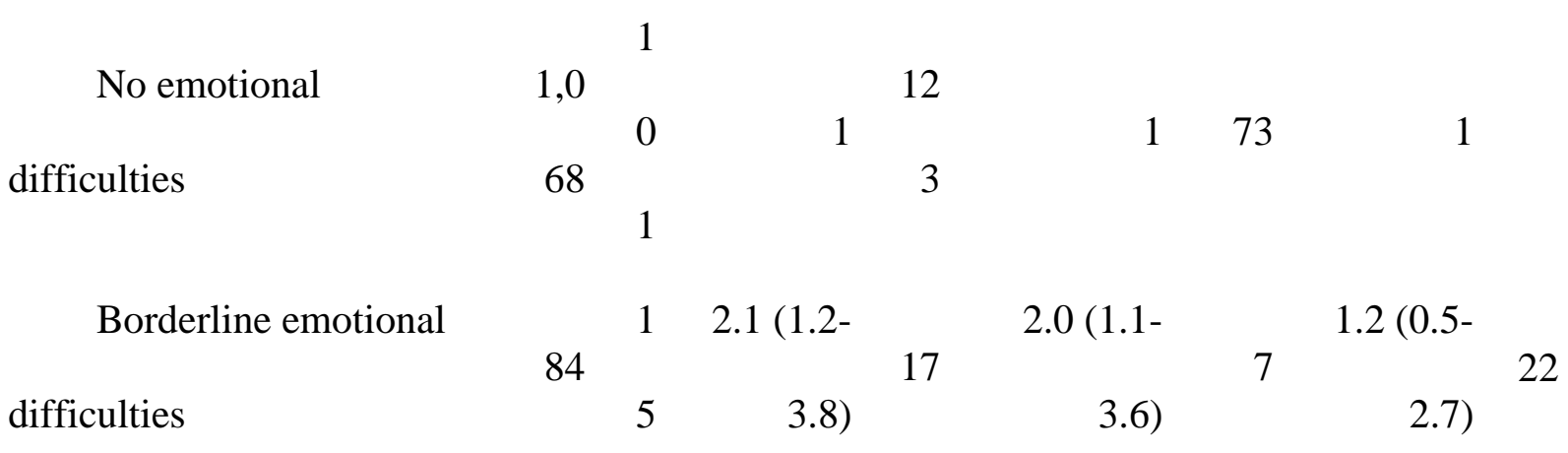


Note: Missings: cohabitants ${ }^{1:} 20$; unemployment $^{2:} 56$; serious parental illness $^{3}: 60 . * \mathrm{P}<0.05$ **Adjusted for gender of the child, maternal education, parental cohabitants, parental employment status, serious parental illness and parental psychiatric hospitalizations.

***Same adjustment as above, restricted to children of parents without a history of psychiatric hospitalizations $(n=35)$ and children of parents with serious illness $(n=48) ; N=1,253$. 